\title{
Phase transformations occurring during the formation of a welded joint from rail steel
}

\author{
Alexey Yuryev, Nikolay Kozyrev*, Roman Shevchenko, Alexey Mikhno, and Olga Gutak \\ Siberian State Industrial University, Novokuznetsk, 654007, Russia
}

\begin{abstract}
The results of dilatometry, metallography and hardness testing of the decomposition process of supercooled austenite of R350LHT steel are presented. During continuous cooling and in isothermal conditions, continuous cooling transformation diagrams of supercooled austenite decomposition of steel R350LHT are constructed.
\end{abstract}

\section{Introduction}

Welding of railway rails is based on detailed understanding of the main characteristics of rail steels. In addition to the chemical composition, these characteristics include data on the position of critical points and the decomposition kinetics of supercooled austenite, on the sensitivity of steel to overheating and grain growth, on the hardenability and physical and mechanical properties of steel. Information on the kinetics of supercooled austenite transformation is of great importance since it serves as a basis for obtaining the hardened layer with required thickness, for selecting modes of heat treatment and ensuring the required indicators of the obtained physical and mechanical properties [1-7].

It should be noted that most types of heat treatment of structural steels are carried out with the heating of the processed material above the critical temperatures As1 or As3, that is, to the temperatures of existence of the high-temperature phase - austenite, and the formation of the final structural steel state in this case occurs during the decomposition of austenite, which was supercooled below the critical points [8].

The most complete characteristic of austenite transformations upon cooling for each steel is the isothermal and CCT diagrams of the decomposition of supercooled austenite.

Isothermal diagrams characterize the austenite decomposition kinetics at a constant supercooling temperature. Such diagrams are illustrative for a comparative assessment of different steels, as well as for revealing the role of alloying and other factors (heating temperature, grain size, plastic deformation, etc.) on the kinetics of decomposition of supercooled austenite [9].

Continuous cooling transformation diagrams characterize the decomposition kinetics of austenite during continuous cooling. These diagrams are less illustrative, but they are of great practical importance, since during heat treatment, the decomposition of austenite occurs with a continuous change in temperature, and not in isothermal conditions. If the cooling rates in different sections of real products are known, then by plotting the

\footnotetext{
*Corresponding author: kozyrev_na@mtsp.sibsiu.ru
} 
corresponding curves of the cooling rates on the CCT diagram, it is possible to determine the temperature of austenite transformations and estimate the resulting structure [10].

The austenite transformation in the subcritical temperature range can develop in several ways with the formation of various structural components. Usually, diffusion, diffusionless and intermediate mechanisms of transformation are distinguished. Each develops according to its own law and kinetics [9]. The diffusion transformation of austenite leads to the formation of excess ferrite or carbide phases and the formation of a ferritocarbide mixture with different degrees of dispersion. Depending on the degree of dispersion, the ferritocarbide mixture is often called pearlite, sorbitol or troostite. Two phases in pearlite (ferrite and cementite) look like alternating, closely spaced plates.

An intermediate transformation of austenite usually takes place at lower temperatures. The temperature range and the kinetics of the intermediate transformation depend mainly on the chemical composition of the austenite. This interval shifts towards lower temperatures with an increase in the content of carbon and alloying elements. A characteristic feature of the intermediate transformation resides in the fact that the development of transformation stops, leaving more or less unconverted austenite, when a certain percentage of decomposition at a given temperature is achieved. The lower the transformation temperature is, the more complete the intermediate transformation is and the less unresolved austenite remains.

Under the influence of intermediate transformation, a change in the composition of the unconverted part of austenite is observed, mainly with respect to carbon, and possibly also with respect to some other elements. Depending on the chemical composition of the steel, unconverted austenite is either enriched or depleted in carbon, or there is no noticeable change in composition.

The products of the intermediate transformation (bainite) have an acicular structure. A diffusionless transformation usually develops at even lower temperatures. It is connected with the formation of martensite and is called martensitic. Unlike diffusion or intermediate transformation, martensitic transformation develops at a very high rate.

As in the intermediate transformation, the martensitic transformation at a given temperature, does not reach the end, leaving some unconverted austenite. The greater the supercooling degree of austenite below the martensite point is, the more complete the martensitic transformation is and the less unconverted austenite remains. The temperature range of martensitic transformation is almost unambiguously determined by the austenite chemical composition. With an increase in the carbon content and most alloying elements, it shifts to the zone of lower temperatures [9].

The structure of martensite crystals depends on the temperature of the martensitic transformation, i.e., the position of the point $\mathrm{Mn}$. At low temperatures of martensitic transformation (high-carbon steels), lamellar (acicular) martensite is formed in the form of a plate or lens. Lamellar crystals have a twinned structure. In most alloyed structural steels, as well as carbon steels, with a content of less than $0.6 \% \mathrm{C}$, lath martensite is formed. Lath martensite consists of thin parallel martensite plates forming a lathe having approximately the same linear dimensions in all directions.

Kinetics of austenite transformations, i.e., the type of the decomposition diagram depends on many factors and, first of all, on the chemical composition of austenite. Therefore, the temperature conditions for the development of one or another transformation can vary within very wide limits.

Broad gauge railway rails of P75 and P65 types are manufactured in accordance with the Russian State Standards GOST 51685-2013 from converter and electric steel. Alloying steel with non-carbide-forming silicon decreases the iron content in the eutectoid, and alloying with carbide-forming manganese increases the carbon content in the eutectoid. 
Both alloying elements shift the S point towards lower carbon contents. Thus, according to the structure in the equilibrium state, the considered R350LHT steel is eutectoid.

In carbon and some low-alloy steels containing non-carbide-forming elements, diffusion and intermediate transformations occur in close temperature ranges. As a result, in isothermal diagrams at temperatures above the martensite point, only kinetic one is usually observed. Silicon and manganese, dissolving in ferrite, increase the stability of austenite and shift the curves of the onset of transformation to the right. It can also be seen in the presented diagrams that silicon shifts the austenite minimum stability to the zone of high temperatures, while manganese, on the contrary, shifts this zone towards lower temperatures [11].

Steel alloying with silicon and manganese also affects the kinetics of the intermediate transformation. Manganese increases the duration of the incubation period of the intermediate transformation, lowers the temperature of the minimum stability of austenite and the maximum rate of transformation. Silicon causes inhibition even at the lowest intermediate transformation temperatures, while it contributes to the maximum saturation of retained austenite with carbon. So, in steels with $0.3 \ldots 0.6 \% \mathrm{C}$, the carbon content in the retained austenite during intermediate transformation can increase $2 \ldots .3$ times.

The alloying elements have no noticeable effect on the martensitic transformation kinetics, but significantly change the position of martensitic points. Manganese significantly lowers the temperature of the onset of martensitic transformation and increases the amount of retained austenite in the hardened steel. Silicon, on the other hand, does not affect the temperature range of the martensitic transformation [11]. These prerequisites formed the basis for the development of a new rail welding technology. The first studies were carried out using R350LHT steel according to EN 13674-1:2017, with the exception of a lower vanadium content, similar to steel grade E76KhF according to GOST R 516852013, used for the production of differentiated heat-strengthened rails at domestic enterprises. To describe the possible structural states that can be obtained at continuous cooling, as well as in isothermal conditions, CCT and isothermal diagrams of the supercooled austenite decomposition of steel under study were constructed and, on the basis of these materials, a new technology for welding differentially heat-strengthened rails was developed.

\section{Materials and methods of research}

Dilatometry was carried out on a Linseis RITA L78 hardening dilatometer with horizontal positioning of samples. To determine the real temperature of the sample under study, a Ktype thermocouple $(\mathrm{Ni}-\mathrm{NiCr}$ ) was used, which was welded to the side surface of the cylindrical samples. Heating was carried out in inert gaseous helium of high purity - grade 6.0 (according to TU 0271-001-45905715-02, purity is $99.9999 \%$ ). Cooling was carried out in a flow of gaseous helium of high purity (grade 6.0). The dilatometric samples under study had the shape of a cylinder with a height of 9-11 mm and a diameter of 3-4 mm. The collection and processing of experimental data was carried out using the WIN - DIL and Linseis Data Evaluation software package.

To determine the position of the critical point As1 (the temperature of the onset of transformation), the sample from the steel under study was heated at a rate of $1.5^{\circ} \mathrm{C} / \mathrm{s}$ to a temperature of $1000{ }^{\circ} \mathrm{C}$. The heating temperature for constructing the CCT and isothermal diagrams was set at $50{ }^{\circ} \mathrm{C}$ above the temperature of the end of transformation. The transformation temperature range was determined by the point of separation of the tangent from the linear section of thermal expansion before and after the phase transformation.

When constructing a CCT diagram of overcooled austenite decomposition of R350LHT steel, the samples from the studied steel were heated at a rate of $1.5^{\circ} \mathrm{C} / \mathrm{s}$ to a temperature of 
$825{ }^{\circ} \mathrm{C}$ with holding at this heating temperature for 15 minutes. Cooling from the heating temperature was carried out at speeds of $100,30,10,7.5,5 ; 1$ and $0.1{ }^{\circ} \mathrm{C} / \mathrm{s}$ up to the temperature of $30^{\circ} \mathrm{C}$. On the CCT diagram of supercooled austenite decomposition, the abscissa shows the time from the moment of the beginning of cooling from the heating temperature.

When constructing an isothermal diagram of overcooled austenite decomposition in R350LHT steel, the samples from the studied steel were heated at a rate of $1.5^{\circ} \mathrm{C} / \mathrm{s}$ to the temperature of $825{ }^{\circ} \mathrm{C}$ with holding at this heating temperature for 15 minutes. It was cooled from the heating temperature to the isothermal holding temperature at a rate of 100 ${ }^{\circ} \mathrm{C} / \mathrm{s}$. Isothermal holding in the supercooled austenite zone was carried out at temperatures of $700,650,600,550,500,450,400,350,300$, and $250{ }^{\circ} \mathrm{C}$. On the isothermal diagram of the supercooled austenite decomposition, the abscissa shows the time from the start of isothermal holding.

Microhardness testing was carried out in accordance with GOST R ISO 6507-1-2007 on the DuraScan 70 microhardness tester manufactured by EMCO-TEST (Austria) for Vickers tests using the restored indentation method by indentation of a four-sided diamond pyramid with a square base at a load of $500 \mathrm{~g}$. On each sample, measurements were performed along two mutually perpendicular diameters from edge to edge. The arithmetic mean of 10 measurements was taken as a hardness number.

Metallographic studies were carried out on microsections of samples using an Olympus GX 51 inverted light microscope at a magnification of 500 times. Image processing was carried out using the SIAMS 700 software and hardware complex for image analysis, as well as using the Olympus Stream Motion software, version 1.8.

Microsections were made by pressing the samples on the unit CitoPress-10 (Struers, Denmark) at a temperature of $120{ }^{\circ} \mathrm{C}$. The total time for pressing and cooling was 5 minutes. The procedure for obtaining microsections was carried out on an automated Tegramin-30 machine (Struers, Denmark). To reveal the structure, the microsection was etched with a $3 \%$ solution of nitric acid in ethyl alcohol. Investigation of the processes of decomposition of supercooled austenite was carried out by dilatometry, metallography and hardness testing.

\section{Experiments and results}

The chemical composition of the investigated steel R350LHT is shown in Table 1.

Table 1. Chemical composition of the investigated steel.

\begin{tabular}{|c|c|c|c|c|c|c|c|c|c|c|}
\hline \multirow{2}{*}{ Steel grade } & \multicolumn{10}{|c|}{ Element content, wt. \% } \\
\hline & C & Si & Mn & $\mathrm{Cr}$ & $\mathbf{N i}$ & V & Al & Мo & $\mathbf{S}$ & $\mathbf{P}$ \\
\hline $\begin{array}{c}\text { Investigated } \\
\text { metal }\end{array}$ & 0.81 & 0.56 & 0.97 & 0.27 & 0.08 & 0.004 & 0.003 & 0.007 & 0.005 & 0.013 \\
\hline $\begin{array}{c}\text { R350LHT } \\
\text { according to EN } \\
13674-1: 2017\end{array}$ & $\begin{array}{r}0.70- \\
0.82\end{array}$ & $\begin{array}{r}0.13- \\
0.60\end{array}$ & $\begin{array}{r}0.65- \\
1.25\end{array}$ & $\leq 0.30$ & $\leq 0.20$ & $\leq 0.030$ & $\leq 0.004$ & $\leq 0.20$ & $\leq 0.025$ & $\leq 0.030$ \\
\hline $\begin{array}{c}\text { E76KhA } \\
\text { according to } \\
\text { GOST 51685- } \\
2013\end{array}$ & $\begin{array}{c}0.71- \\
0.82\end{array}$ & $\begin{array}{r}0.25- \\
0.60\end{array}$ & $\begin{array}{r}0.75- \\
1.25\end{array}$ & $\begin{array}{r}0.20- \\
0.80\end{array}$ & $\leq 0.20$ & $\begin{array}{r}0.03- \\
0.15\end{array}$ & $\leq 0.004$ & - & $\leq 0.020$ & $\leq 0.020$ \\
\hline
\end{tabular}

From the data presented in Table 1, it can be seen that in terms of the content of chemical elements, the studied metal meets the requirements of EN 13674-1: 2017 for steel grade R350LHT, as well as steel grade E76KhF according to GOST R 51685-2013, with 
the exception of vanadium, the content of which is lower than the requirements of the standard.

To determine the heating temperature for austenitization before continuous cooling for constructing a CCT diagram of supercooled austenite decomposition, continuous heating was carried out to a temperature of $1000{ }^{\circ} \mathrm{C}$ at a rate of $1.5^{\circ} \mathrm{C} / \mathrm{s}$, which corresponds to the heating rate by hot furnace loading.

From the results of continuous heating, the critical point As1 and the temperature of the end of the transformation during continuous heating were determined from the dilatometric curve using the tangent method. Thus, the temperature of As1 was $708{ }^{\circ} \mathrm{C}$, and the temperature of the end of the transformation was $775{ }^{\circ} \mathrm{C}$. Thus, in the study an austenitization temperature of $825{ }^{\circ} \mathrm{C}$ was chosen for heating, which exceeds the temperature of the end of transformation by $50{ }^{\circ} \mathrm{C}$.

Heating for the subsequent study of the supercooled austenite decomposition during continuous heating was carried out at a rate of $1.5{ }^{\circ} \mathrm{C} / \mathrm{s}$ to a temperature of $825^{\circ} \mathrm{C}$. The holding period at the austenitizing temperature was 15 minutes. Cooling was carried out at speeds of $100,30,10,7.5,5 ; 1$ and $0.1^{\circ} \mathrm{C} / \mathrm{s}$ up to a temperature of $30^{\circ} \mathrm{C}$.

The temperatures of the beginning and end of the transformation during heating and cooling were determined from the point of tangent separation from the linear section of thermal expansion before and after the phase transformation.

Microsections were made from the samples after dilatometric measurements during the heat treatment according to the specified modes. Their microstructure was investigated and microhardness testing was carried out.

Based on the results of the study, a CCT diagram of the supercooled austenite decomposition was built (Fig. 1).

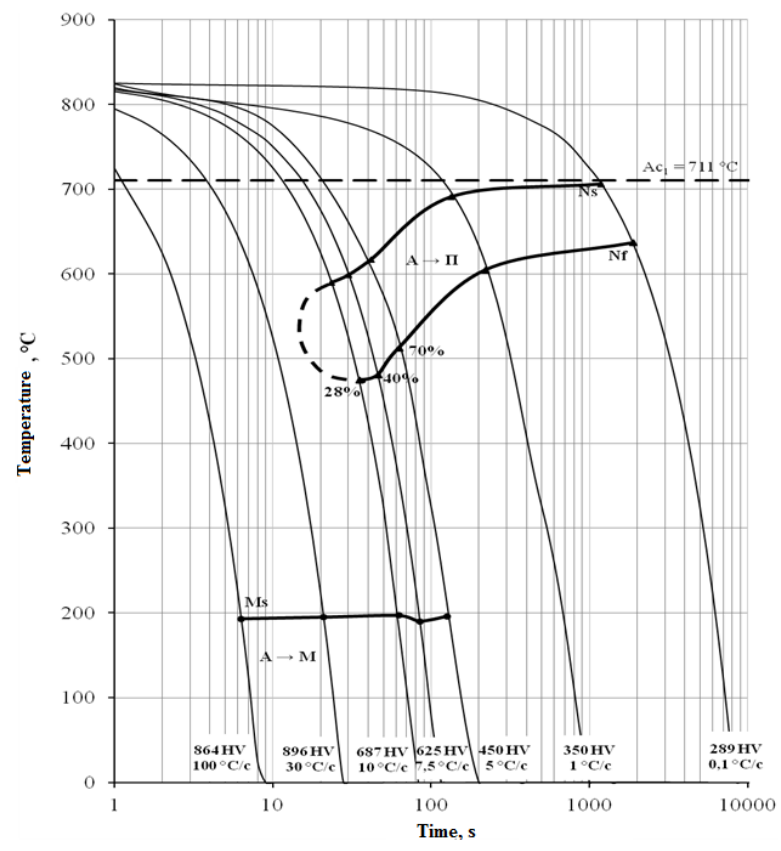

Fig. 1. CCT diagram of supercooled austenite decomposition in R350LHT steel.

When cooled at rates of 0.1 and $1{ }^{\circ} \mathrm{C} / \mathrm{s}$, the austenite of R350LHT steel undergoes a pearlite decay. The transformation temperature range is between $706-637{ }^{\circ} \mathrm{C}$ and $691-$ 
$617{ }^{\circ} \mathrm{C}$, respectively. Pearlite colonies were found in the structure of the samples after dilatometric studies, which is shown in Fig. 2 a-b.

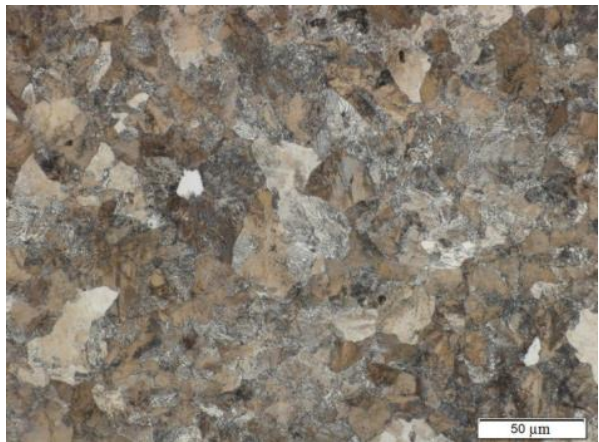

a

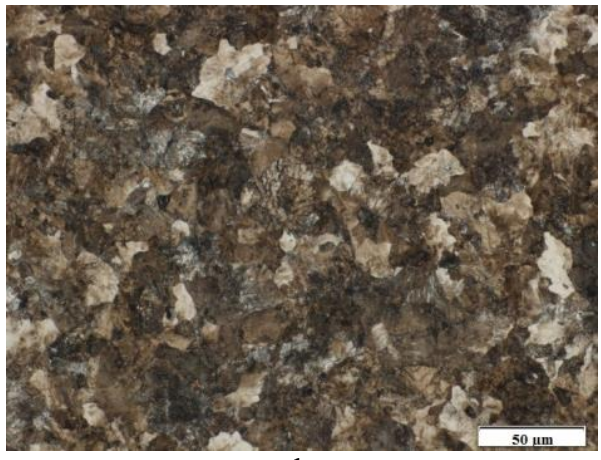

b

Fig. 2. Структура стали R350LHT после непрерывного охлаждения со скоростями 0,1 (а) и 1 ${ }^{\circ} \mathrm{C} / \mathrm{c}$ (б). Fig. 2. Structure of R350LHT steel after continuous cooling at rates of 0.1 (a) and $1{ }^{\circ} \mathrm{C} / \mathrm{s}$ (b).

It should be noted that after cooling at a lower rate, the pearlite structure is coarser and has a lower hardness - $289 \mathrm{HV}$ due to the higher temperature range of transformation, where diffusion processes associated with the austenite transformation into pearlite take place more actively. At a higher cooling rate $\left(1{ }^{\circ} \mathrm{C} / \mathrm{s}\right)$, the hardness of the steel increases to $350 \mathrm{HV}$, which is caused by a more dispersed ferritocarbide mixture.

An increase in the cooling rate to $5{ }^{\circ} \mathrm{C} / \mathrm{s}$ causes the development of the transformation by two mechanisms: pearlite and martensitic. In the temperature range $604-513{ }^{\circ} \mathrm{C}$, the pearlite transformation of austenite develops. In this case, the percentage of the ferritocarbide mixture in the structure is $70 \%$ (Fig. 3a). Upon further cooling, the austenite remaining after pearlite decomposition transforms into martensite at temperatures below $196{ }^{\circ} \mathrm{C}$. The hardness of the steel is $450 \mathrm{HV}$.

Cooling at a rate of $7.5^{\circ} \mathrm{C} / \mathrm{s}$ also causes the austenite transformation by the pearlite and martensitic mechanism. In this case, $40 \%$ of austenite turns into pearlite within the range of $599-481{ }^{\circ} \mathrm{C}$ (Fig. 3 b), and the remaining austenite turns into martensite at temperatures below $190{ }^{\circ} \mathrm{C}$. In other words, the amount of martensite in the structure increases leading to an increase in hardness up to $625 \mathrm{HV}$.

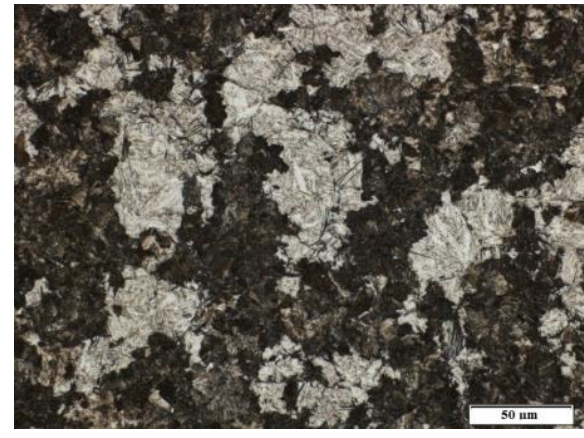

a

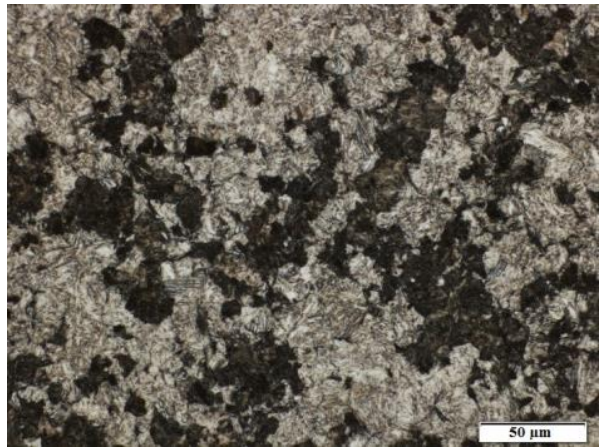

b

Fig. 3. Structure of R350LHT steel after continuous cooling at rates of 5 (a) and $7.5^{\circ} \mathrm{C} / \mathrm{s}$ (b). 
A further increase in the cooling rate from a temperature of $825^{\circ} \mathrm{C}$ to $10{ }^{\circ} \mathrm{C} / \mathrm{s}$ causes a decrease in the temperature range of pearlite decomposition of austenite to $590-475{ }^{\circ} \mathrm{C}$. In this case, the proportion of austenite transformed into pearlite decreases to $28 \%$ (Fig. 4 , a). As a result, the hardness of R350LHT steel is at a high level $-687 \mathrm{HV}$.

Upon cooling at a rate of $30^{\circ} \mathrm{C} / \mathrm{s}$, a martensitic structure is observed in the structure, which indicates the absence of pearlite transformation in R350LHT steel at such a cooling rate (Fig. 4, b). The hardness of the investigated steel in this case is equal to the hardness of the hardening martensite and is $896 \mathrm{HV}$.

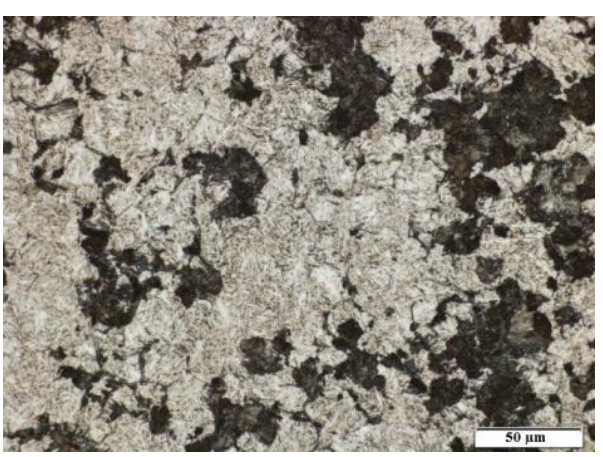

a

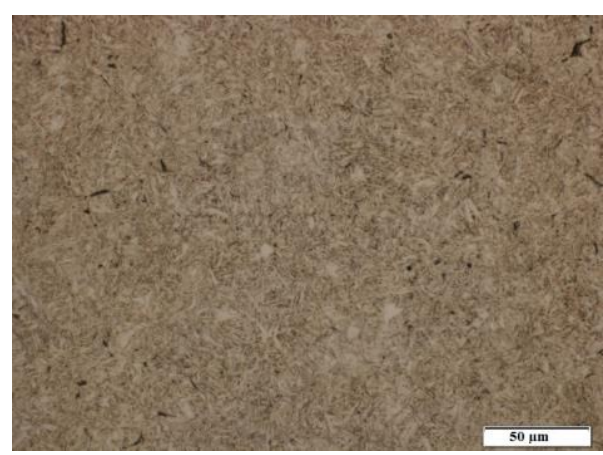

$\mathrm{b}$

Fig. 4. Structure of R350LHT steel after continuous cooling at rates of 10 (a) and $30^{\circ} \mathrm{C} / \mathrm{s}$ (b).

Cooling at a rate of $100{ }^{\circ} \mathrm{C} / \mathrm{s}$ also leads to suppression of pearlite transformation and the development of martensitic transformation at temperatures below $193{ }^{\circ} \mathrm{C}$ (Fig. 5). The hardness of the steel in this case is also equal to the hardness of the hardened martensite and is $864 \mathrm{HV}$.

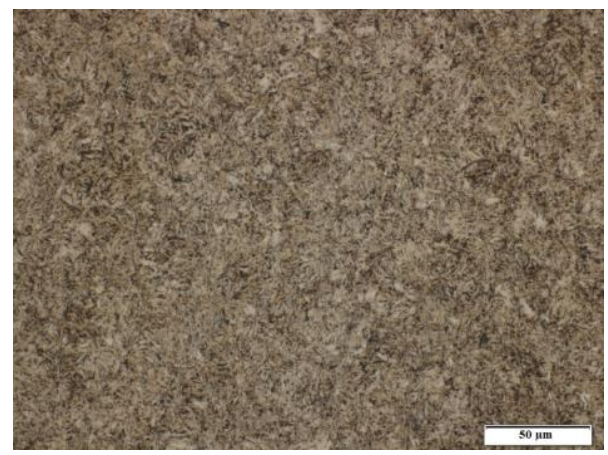

Fig. 5. Structure of R350LHT steel after continuous cooling at a rate of $100^{\circ} \mathrm{C} / \mathrm{s}$.

\section{Conclusions}

1. Based on the results of dilatometry, metallography and hardness testing of process of of supercooled austenite decomposition in steel R350LHT during continuous cooling and in the isothermal conditions, CCT diagrams of supercooled austenite decomposition of steel R350LHT were built;

2. In the study of supercooled austenite decomposition during continuous cooling, it was found that cooling at rates of 0.1 and $1{ }^{\circ} \mathrm{C} / \mathrm{s}$ causes the austenite decomposition in R350LHT steel by the pearlite mechanism. In the range of rates from 5 to $10{ }^{\circ} \mathrm{C} / \mathrm{s}$, the decomposition of austenite occurs according to the pearlite and martensitic mechanisms, 
which leads to the formation of a pearlite-martensite structure. When the austenite of the steel under study is cooled at rates of 30 and $100{ }^{\circ} \mathrm{C} / \mathrm{s}$, austenite transforms according to the martensitic mechanism with obtaining a martensitic structure of high hardness. With an increase in the cooling rate of R350LH steel, an increase in hardness is observed from 289 (at $0.1{ }^{\circ} \mathrm{C} / \mathrm{s}$ ) to $864-896 \mathrm{HV}$ (at 100 and $30{ }^{\circ} \mathrm{C} / \mathrm{s}$, respectively).

3. To ensure the guaranteed pearlite structure, the cooling of R350LHT steel should be carried out at a rate of no more than $1{ }^{\circ} \mathrm{C} / \mathrm{s}$. At the same time, it should be noted that it is necessary to conduct additional studies of the austenite decomposition kinetics in R350LHT steel during continuous cooling at rates of $1-5^{\circ} \mathrm{C} / \mathrm{s}$ to clarify the limiting cooling rates at which a complete pearlite structure is created.

4. To assess the effect of vanadium content on the austenite transformation kinetics in rail steel, the study will be continued for $\mathrm{E} 76 \mathrm{KhF}$ rail steel.

\section{References}

1. E. Polevoy, K.V. Volkov, et al, Development of Technology for the Production of Differentially Heat-strengthened Rails at OJSC "EVRAZ ZSMK" (2014)

2. J. Myers, G.H. Geiger, D.R. Welding Journal, 258, 8-19 (1982)

3. L.B. Tikhomirova, Bulletin of the South Ural state university. Series "Metallurgy", 16(3), 90-95 (2016)

4. A. Konovalov et al., Theory of Welding Processes, 559 (2007)

5. L. Weingrill, J. Krutzler, N. Enzinger, Materials Science Forum, 879 (2016)

6. R. Yamamoto, Y. Komizu, Y. Fukada, Welding International, 28(7), 510-520, (2014)

7. F. Mitsuru, N. Hiroaki, N. Kiyoshi, JFE Technical Report, 20, 159-163 (2015)

8. M. Blanter, Heat treatment theory (1984)

9. A. Popov, L. E. Popova, Isothermal and CCT diagrams of supercooled austenite decomposition (1985)

10. M. Goldstein, S.V. Grachev, Yu.G. Veksler, Special steels (1985)

11. V.I. Zyuzin, Influence of alloying elements on the kinetics of isothermal transformation and decomposition of austenite, Proceedings of the Ural Branch of the USSR Academy of Sciences (1941) 